Journal of Computer Science 5 (12): 1028-1033, 2009

ISSN 1549-3636

(C) 2009 Science Publications

\title{
Efficient Approach for Security Information Retrieval by Using Grid
}

\author{
Hameed Ullah Khan \\ Centre of Excellence in Information Assurance, \\ Department of Information Systems, College of Computer and Information Sciences, \\ King Saud University, Riyadh, Kingdom of Saudi Arabia
}

\begin{abstract}
Problem statement: This article communicated an approach for determining the exact location/position of the target(s) (human) by applying Grid (matrix) method. Approach: The MainGrid in-return further grouped into Mini-Grids; which will provide the target(s) information. To accomplish this idea the whole scenario is divided into three phases. Results: In the first phase data is collected from the targeted area, in second phase data activation/procedure(s) takes place at the target(s), whereas in the third phase data was processed to obtain the required results for the target(s). Conclusion/Recommendations: This study provided details on the first phase. It is faster in gathering data about the exact target location. It is also worth noticing that this approach is efficient, accurate and require very less processing time. The results achieved by this approach are highly reliable.
\end{abstract}

Key words: Information technology, security system, computer network

\section{INTRODUCTION}

The horrific scale of destruction caused by the terrorist attacks has ushered in a period of global uncertainty on various fronts: political, economic, military and technological. In essence, terrorism involves the use of violence to achieve political objectives, by deliberately trying to inflict mass casualties or cause other forms of costly damage against civilian/government populations. It is a form of psychological warfare, as the terrorist acts are designed to frighten targeted populations and attract global attention $^{[1-3]}$.

Currently all nations are facing an economic crisis coupled with increasing insurgency concerns from militant organizations. Almost 40-60 percent of the budget of these nations is being spent on trying to accommodate these challenges, but still the results achieved are not encouraging ${ }^{[4-7]}$. This is mainly due to the fact that there are less sources of information involved in such undertakings and the field of Information Technology (IT) has not been fully utilized to stem these crises ${ }^{[8]}$.

To successfully, access, collect and timely interpret intelligent information is critical. Technology can be deployed to secure, control and deny critical access and information, in order to reduce the capability to inflict damage. The current trends in technological development point toward a combined use of several technologies such as biological technologies, robotics, information technology and nanotechnology in the fight against global terrorism. Developments in information technology facilitate data collection, analysis, security and integration; robotics can facilitate remote surveillance, the distancing of dangerous substances from human control, while biotechnologies can facilitate identification of biological hazards, forensic tools $^{[9-12]}$.

Many countries have introduced identity cards and passports with a fingerprint and facial biometric/ facial-recognition and fingerprint-biometric technologies to control immigration. Scientific discoveries and breakthroughs, especially in information technology, are redefining how to plan, mobilize and engage in battles. For instance, consider the Internet and other national communication infrastructures. Similarly, there is a budding collection of research in the computer and information sciences domains that addresses new algorithms, techniques, models and methods for engaging in the battlefield with insights on everything from sensor technology to complex information discovery models. Research on terrorism is housed in the legal domain, philosophical studies (especially in ethics and law), management (especially crisis management), health sciences and engineering sciences. There is, however, a dart of cross-disciplinary research that involves meshing of two disciplines, e.g., computer science and public policy $^{[13-15]}$.

The modern information theory and communication theory, it is often desirable to apply matrix techniques to simplify the problem by giving it 
Table 1: The Grid network

Main-Grid-0 $\quad$ Main-Grid-1 $\quad$ Main-Grid-2 $\quad$ Main-Grid-3 $\quad$ Main-Grid-4 $\quad$ Main-Grid-5 $\quad$ Main-Grid-6 $\quad$ Main-Grid-7 $\quad$ Main-Grid-8 $\quad$ Main-Grid-9

Main-Grid-10 Main-Grid-11 Main-Grid-12 Main-Grid-13 Main-Grid-14 Main-Grid-15 Main-Grid-16 Main-Grid-17 Main-Grid-18 Main-Grid-19

Main-Grid-90 Main-Grid-91 Main-Grid-92 Main-Grid-93 Main-Grid-94 Main-Grid-95 Main-Grid-96 Main-Grid-97 Main-Grid-98 Main-Grid-99

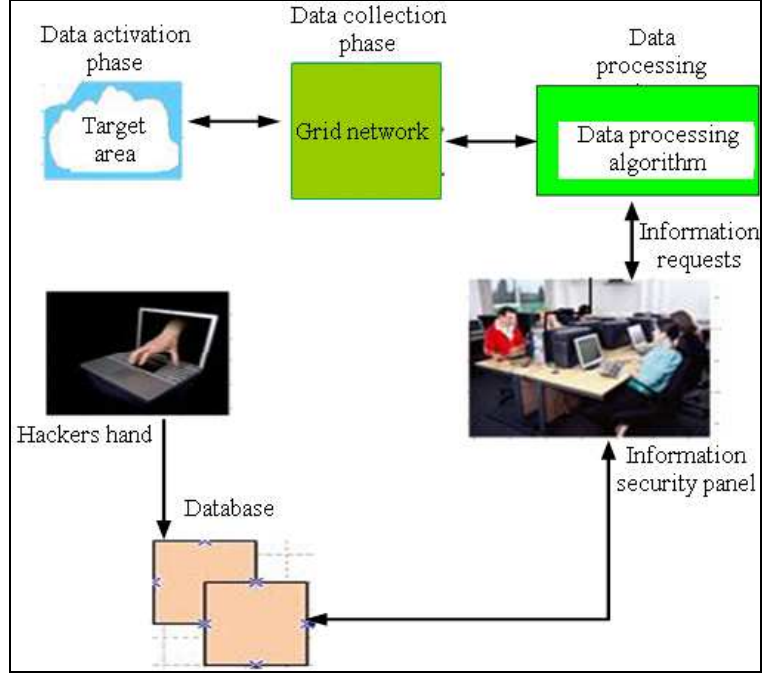

Fig. 1: Proposed architecture

the form of mathematical expression, on which logic can later be applied ${ }^{[16-19]}$. Previously many methods are adopted for scanning objects such as laser beam, radio frequency, e-tags, cards, wireless technology and sensor for information gathering. The source used for information collection and, later processing this information to achieve the desired target, is implemented by using Grid $^{[20-22]}$.

This paper is divided into different sections and sub-section; the next section communicates materials and methods, with sub-section on the proposed architecture followed by the complete theory for Grid are analyzed and followed by the implementation of the algorithm. In the second last section results are given and in the last section conclusions are discussed.

\section{MATERIALS AND METHODS}

Proposed architecture: The proposed architecture, illustrated in Fig. 1, involves data collection from the area and fed into the processing phase. If the alert signal is raised from the database for certain area, the security panel desk will observe alert signal on their screen for further action. These alert signals have been clustered together by standard correlation and datamining techniques for further information processing. Proposed approach applies a recognition process to this observation by using the databases search.
Table 2: Algorithm reading sequence for information

\begin{tabular}{llll}
\hline Main-Grid & Mini-Grid & Row & Column \\
\hline 0 & 02 & 3 & 4 \\
\hline \multicolumn{4}{l}{ Table 3: Algorithm reading sequence for } \\
\hline Main-Grid & Mini-Grid & Row & Column \\
\hline 0 & 20 & 3 & 4 \\
\hline
\end{tabular}

This process involves first identifying individual(s) and then aggregating these observations into larger, coherent sets (composition). The results are then presented, along with information requests for that recommend targeted investigations for confirmation and alert the security personal around that individual(s) in the area/crowd to block in-progress attack(s). It is very important to make sure that database is made high level secured during operations.

Theoretical approach: A 'Grid' or 'Square matrix' will read data continuously from the area/ground and send it to the database for processing. Each Grid is a combination of 'Mini-Grids' with unique addresses. The structure of Grid is explained as follows:

Grid network: When need arises the Grid network will be activated as shown in Table 1.

The size of the Grid network is fixed as shown in Table 1. The number of Grid network used depends during operation(s); one or many Grid(s) network may be involved for information collection(s), so it may be sequential or random selection of Main-Grid(s) from the Grid network.

Activating Main-Grid: All the grids in the Grid network are known as Main-Grids as shown in Table 1. The concerned Main-Grid in-return is the combination of Mini-Grids, which is activated for the information. The range of the sub-sections is set up inside the MiniGrid, for example, if information is reported from the number '00234'; (the reading sequence is from right to left) which in-return represents column number ' 4 ', row number ' 3 ', Mini-Grid number ' 02 ' and finally MainGrid number ' 0 ' as shown in Table 2.

The field width for a column is only one character, in-case of a row it is also one character, for Mini-Grid two characters and for Main-Grid two characters. The proposed algorithm will read the source number(s) from right to left. In the above number '00234', let suppose the position of ' 0 ' is changed, the new number '02034' will have different representation as shown in Table 3. 
Table 4: The Main-Grid-0 and Mini-Grid-00 structures

Main-Grid-0 $\quad$ Mini-Grid-0 $\quad$ Mini-Grid-1 $\quad$ Mini-Grid-2 $\quad$ Mini-Grid-3 $\quad$ Mini-Grid-4 Mini-Grid-5 Mini-Grid-6 Mini-Grid-7 Mini-Grid-8 $\quad$ Mini-Grid-9

Mini-Grid-0 Mini-Grid-00

Mini-Grid-1

Mini-Grid-2

Mini-Grid-3

Mini-Grid-4

Mini-Grid-5

Mini-Grid-6

Mini-Grid-7

Mini-Grid-8

Mini-Grid-9

Table 5: Mini-Grid-00 with sub-sections structure

\begin{tabular}{|c|c|c|c|c|c|c|c|c|c|c|c|c|}
\hline $\begin{array}{l}\text { Main-Grid-0 } \\
\text { Mini-Grid-00 }\end{array}$ & & & $\mathrm{C}_{0}$ & $\mathrm{C}_{1}$ & $\mathrm{C}_{2}$ & $\mathrm{C}_{3}$ & $\mathrm{C}_{4}$ & $\mathrm{C}_{5}$ & $\mathrm{C}_{6}$ & $\mathrm{C}_{7}$ & $\mathrm{C}_{8}$ & $\mathrm{C}_{9}$ \\
\hline & Sub-section 0 & $\mathrm{R}_{0}$ & \multicolumn{10}{|c|}{$\mathrm{G}_{00} \mathrm{R}_{0} \mathrm{C}_{0}$} \\
\hline & Sub-section 1 & $\mathrm{R}_{1}$ & & & & & & & & & & \\
\hline & Sub-section 2 & $\mathrm{R}_{2}$ & & & & & & & & & & \\
\hline & Sub-section 3 & $\mathrm{R}_{3}$ & & & & & & & & & & \\
\hline & Sub-section 4 & $\mathrm{R}_{4}$ & & & & & & & & & & \\
\hline & : & $\mathrm{R}_{5}$ & & & & & & & & & & \\
\hline & : & $\mathrm{R}_{6}$ & & & & & & & & & & \\
\hline & : & $\mathrm{R}_{7}$ & & & & & & & & & & \\
\hline & & $\mathrm{R}_{8}$ & & & & & & & & & & \\
\hline & Sub-section 9 & $\mathrm{R}_{9}$ & & & & & & & & & & \\
\hline
\end{tabular}

Table 6: Main-Grid and Mini-Grid representation for Number 57

Main-Grid-0

Mini-Grid-00

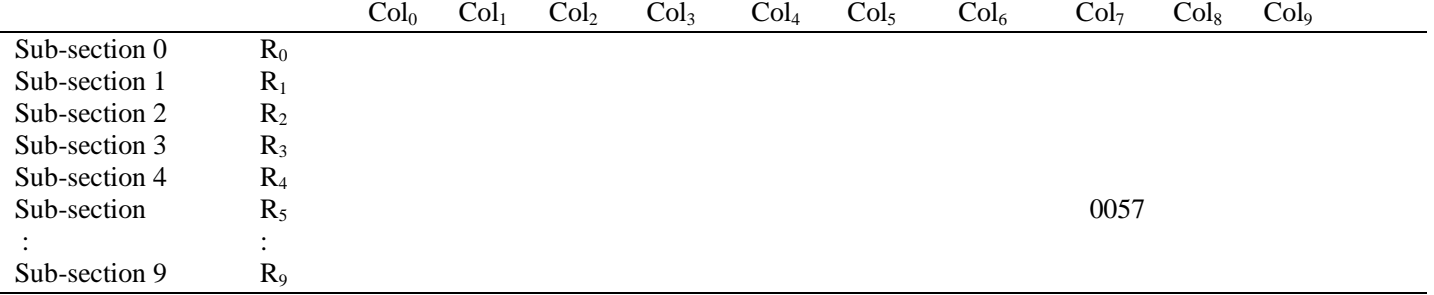

When ever change(s) in positions of numbers occur that will be immediately reported according to its address position to activate the concern Main-Grid or Mini-Grid.

Suppose from the Grid network, the Main-Grid-0 is selected and in-return the Mini-Grid-00 is activated later, then the complete coverage of information is as shown in Table 4.

Table 4 shows the Main-Grid-0 schema, starting from Mini-Grid-00 and terminating at Mini-Grid-99. The entire Main-Grid-0 sub-sections (Mini-Grids) will hold a unique address. The next Mini-Grid in operation will be either Mini-Grid-01 or Mini-Grid-10 or any other Mini-Grid(s). If the area is not entirely covered by Main-Grid-0 then another Main-Grid-1 or any one in sequentially/randomly will be deployed for information collection.

Mini-Grid Internal structure: Each Main-Grid is the combinations of $(10 \times 10)$ Mini-Grids, see Table 4. Each Mini-Grid in-return having Sub-sections $\left(\left(\mathrm{R}_{0}-\mathrm{R}_{9}\right)\right.$ and $\left.\left(\mathrm{C}_{0} \mathrm{C}_{9}\right)\right)$ as shown in Table 5. A Mini-Grid-0 can hold a total of 100 addresses, that is, starting from '0000' and terminating at '0099'.

Let's suppose data received at Main-Grid-0 at the location of Mini-Grid-00 then the data received will be '00000' as shown in Table 5.

Similarly, in Mini-Grid-01 the starting address is '0100' at location $\mathrm{G}_{01} \mathrm{R}_{0} \mathrm{C}_{0}$ and the final address is '0199' at location $\mathrm{G}_{01} \mathrm{R}_{9} \mathrm{C}_{9}$. For Mini-Grid-02 starting address is '0200' at location $\mathrm{G}_{02} \mathrm{R}_{0} \mathrm{C}_{0}$ and terminating addresses '0299' at location $\mathrm{G}_{02} \mathrm{R}_{9} \mathrm{C}_{9}$ and so on.

Where as the sub-section is the representation of row(s) and column(s). The combination of a row number and a column number represents the address for that particular sub-section. Each address of sub-section is unique in the Mini-Grid, such as; $\mathrm{G}_{00} \mathrm{R}_{0} \mathrm{C}_{0}$ is the only address in the complete Mini-Grid-00 set-up.

Experimental study: Let's suppose the number received from source is only ' 57 '. As this number is composed of two digits therefore it belongs to MainGrid-0 and Mini-Grid-00. The number representation is as shown in Table 6. 
J. Computer Sci., 5 (12): 1028-1033, 2009

Table 7: Main-Grid and Mini-Grid structure for number 157

\begin{tabular}{|c|c|c|c|c|c|c|c|c|c|c|c|c|}
\hline $\begin{array}{l}\text { Main-Grid-0 } \\
\text { Mini-Grid-01 }\end{array}$ & & & $\mathrm{Col}_{0}$ & $\mathrm{Col}_{1}$ & $\mathrm{Col}_{2}$ & $\mathrm{Col}_{3}$ & $\mathrm{Col}_{4}$ & $\mathrm{Col}_{5}$ & $\mathrm{Col}_{6}$ & $\mathrm{Col}_{7}$ & $\mathrm{Col}_{8}$ & $\mathrm{Col}_{9}$ \\
\hline & $\begin{array}{l}\text { Sub-section } 0 \\
\text { Sub-section } 1 \\
\text { Sub-section } 2 \\
\text { Sub-section } 3 \\
\text { Sub-section } 4 \\
\text { Sub-section } \\
: \\
\text { Sub-section } 9 \\
\end{array}$ & $\begin{array}{l}\mathrm{R}_{0} \\
\mathrm{R}_{1} \\
\mathrm{R}_{2} \\
\mathrm{R}_{3} \\
\mathrm{R}_{4} \\
\mathrm{R}_{5} \\
\vdots \\
\mathrm{R}_{9}\end{array}$ & & & & & & & & 0157 & & \\
\hline $\begin{array}{l}\text { Table 8: Main- } \\
\text { Main-Grid-6 } \\
\text { Mini-Grid -16 }\end{array}$ & and Mini-Gric & ure $f$ & aber 61 & 678 & $\mathrm{Col}_{2}$ & $\mathrm{Col}_{3}$ & $\mathrm{Col}_{4}$ & $\mathrm{Col}_{5}$ & $\mathrm{Col}_{6}$ & $\mathrm{Col}_{7}$ & $\mathrm{Col}_{8}$ & $\mathrm{Col}_{9}$ \\
\hline & $\begin{array}{l}\text { Sub-section } \\
\text { Sub-section } \\
\text { Sub-section } \\
\text { Sub-section } \\
\text { Sub-section } \\
: \\
\text { Sub-section } \\
\text { Sub-section } \\
\text { Sub-section }\end{array}$ & $\begin{array}{l}\mathrm{R}_{0} \\
\mathrm{R}_{1} \\
\mathrm{R}_{2} \\
\mathrm{R}_{3} \\
\mathrm{R}_{4} \\
\vdots \\
\mathrm{R}_{7} \\
\mathrm{R}_{8} \\
\mathrm{R}_{9}\end{array}$ & & & & & & & & & 1678 & \\
\hline
\end{tabular}

In this case ' 7 ' is first digit which represents column no ' $\mathrm{Col}_{7}$ ', where as ' 5 ' is second digit which represents row no ' $R_{5}$ ' and the Mini-Grid and MainGrid numbers are not available. The algorithm will generate ' 00 ' and ' 0 ' respectively to recognize it as a Mini-Grid-00 and part of Main-Grid-0.

Similarly another data received from source is ' 157 '. As the number is composed of three digits therefore it belongs to Main-Grid-0 and Mini-Grid-01. The number representation is as shown in Table 7.

In this case ' 7 ' is first digit which will represent column no ' $\mathrm{Col}_{7}$ ', where as ' 5 ' is second digit which represents row no ' $R_{5}$ ' and ' 1 ' is last digit which represents the Mini-Grid-01 and the Main-Grid number is not available. The algorithm will generate ' 0 ' to recognize it as belong to Main-Grid-0.

Another number received from source is '61678'. As the number is composed of five digits therefore it belongs to Main-Grid-6 and Mini-Grid-16. The number representation is shown in Table 8 .

In this case ' 8 ' is first digit which will represent column no ' $\mathrm{Col}_{8}$ ', where as ' 7 ' is second digit which represents row no ' $\mathrm{R}_{7}$ ' and ' 16 ' are two digits which represent the Mini-Grid-16, whereas number ' 6 ' represent the Main-Grid-6.

Algorithm implementation: The number received by the algorithm is in the integer data type and is stored in a buffer. The reading process of numeric characters starts from right to left direction and then the positions of column, row, Mini-Grid and Main-Grid are adjusted. The complete process is represented in the procedural form is given by:

PROCEDURE Grid \{start reading the data in Grid

VARIABLES

Main-Grid, Mini-Grid, Row, Column,

Number, Length = Integer; $\{$ data type $\}$

BEGIN

Initialise Grid \{see Table 1 and 2 \}

Input: Number $\mathrm{N}$ \{N length of characters

Read length of Number $N$ ssee Table $1 \& 2$ \}

Column $=(\mathrm{N}-1)\{$ position of Column $\}$

Read Number (N-1) \{read the number for Column

Row $=((\mathrm{N}-1)-1)\{$ select the Row from right side $\}$

Read Number ((N-1) -1) \{read for Row selection

Mini-Grid = (((N-1)-1)-1) $\{$ Mini-Grid number $\}$

Read Number (((N-1) -1)-1) \{read Mini-Grid

Main-Grid $=$ Character(s) $\{$ the Main-Grid no $\}$

Read Number Character(s) \{all nos for Main-Grid END

The algorithm sets up the table and reads the numbers from buffer. Then it calculates the column by selecting the first character from the input number starting from right side. From the remaining number the position of row is calculated by selecting the next character in sequence and then from the remaining number(s) for the Mini-Grid and all the remaining number(s) will yield the position for the Main-Grid. 


\section{RESULTS AND DISCUSSION}

The algorithm receives the number (minimum one character as an entry data), e.g., cases illustrated, in Table 6-8 as a demonstration. During experimental phase different lengths of numbers were fed and the results achieved were vary fast and reports generated as very encouraging. Further, proposed algorithm was easy in both designing and implementation. The old conventional systems, such as a walk-through gate and metal detectors all delivered their best possible services to the community at their own days. Now it's the time for change to manage huge flow of data with high speed processing techniques, by avoid delays and get quicker information to detect the culprit(s) and defuse the disaster spot well before time. Furthermore, new trends and new methods must be deployed to provide security to human lives/properties and yield high quality and promising results to minimize disaster damages by providing information in-advance.

\section{CONCLUSION}

The results achieved by simulation, which was inco-operated with the Computer Graphics approach and then applied together and the results observed were promising. The number of Columns and Rows can be increased to any length, that is, to yield a larger size of Mini-Grid and Main-Grids. Secondly, this technique can be applied for storing and retrieving data or movement of position in the shortest possible time, which is one of the major advantages as compared to other approaches.

Future application areas: This approach can be applied in several different areas, such as, in case of scientific uses it can be applied successfully in finding position of neuron in the Neural-Network and in the case of Computer Networking, the expected node detection is easy and efficiently possible. Commercially, it can be used in controlling lifts to reach to the required height, both in aero-drum hangers (plane industry) and in the warehouses for loading and un-loading goods, etc. In defence sector it has possible applications for finding and measuring, distance and direction for targets. As far as minor/delicate surgical procedures can be performed by using robots with this approach. Above all it has enormous application in the field of security.

\section{ACKNOWLEDGEMENT}

A word of thanks to Prof. Mahboob-ur-Rehman for reading the script willingly inspite of his busy schedule. Thanks to my wife for her patience and understanding while I was composing my research. Thanks are also due to Mr. Zahid Ullah, Mr. Maqsood Muhmud and Mr. Ashan Ullah for assisting on the programming aspect of the paper. I deeply acknowledge the support extended on R and D by the King Saud University, Riyadh, Kingdom of Saudi Arabia. I extend my sincere gratitude to the Dean College of Computer and Information Sciences (CCIS) and Chairman Information Systems (IS) department for their continuous encouragement, support and providing the required facilities to make this research possible. Finally, thanks are also due to all those whom contributed to make this research successful.

\section{REFERENCES}

1. Samaraweera, D., 2009. Budget not defending country from global economic crisis, say professionals and exporters.

http://sundaytimes.lk/081109/FinancialTimes/ft301 2.html

2. CAW., 2009. Federal budget again fails workers hurt by economic crisis. http://www.caw.ca/en/5421.htm

3. Daniel, D., 2009. Global economic crisis deeper than expected. http://www.ips.lk/events/workshops/18_2_global_e co_crisis/global_economic.pdf

4. Bogis, A., 2009. Troubled budgets and homeland security.

http://belfercenter.ksg.harvard.edu/analysis/inform edinsight $/$ ? $=653$

5. Watada, J. and Z.B. Musaand, 2008. Tracking human motions for security system. Proceeding of the SICE Annual Conference, Aug. 2008, Tokyo, Japan, $\quad$ pp: 3344-3349. DOI: 10.1109/SICE.2008.4655242

6. McKenna, T., 2003. Video surveillance and human activity recognition for anti-terrorism and force protection. Proceedings IEEE Conference on Advanced Video and Signal Based Surveillance, July 21-22, IEEE Xplore Press, USA., pp: 2-7. DOI: 10.1109/AVSS.2003.1217892

7. Peter, A.J., F.L. Teresa and L.M. Karen, 2005. Identifying terrorist activity with AI planrecognition technology. Am. Assoc. AI Mag., 26: 73-81.

http://www.aaai.org/ojs/index.php/aimagazine/artic le/download/1827/1725 
8. Cohen, E.A., 2002. Making the Nation Safer: The Role of Science and Technology in Countering Terrorism. National Academy Press, ISBN: 0309084814, pp: 440.

9. Brian, T. C. Derodeff, W.P. Crowell D. Dunkel, 2007. Physical and Logical Security Convergence: Powered By Enterprise Security Management, 1st Edn., Syngress, ISBN: 9781597491228, pp: 592.

10. Progressive Policy Institute, 2002. Technology's role against terrorism.

http://license.icopyright.net/user/viewFreeUse.act?f uid=NTk1MzcyNA\%3D\%3D

11. New York Police Department, 2008. Civil rights group sues NYPD over city surveillance plan. http://govtsecurity.com/state_local_security/groupsues-nypd-0918

12. Homeland Security, 2004. Risks of terrorism to information technology and to critical interdependent infrastructures. http://jobfunctions.bnet.com/abstract.aspx?docid=1 17991

13. Lewis, J.W., 2007. Precision terror: Suicide bombing as control technology. Int. Stud. Program, 19: 223-245. DOI: 10.1080/09546550701246890

14. Iskold, A., 2007. Technology and Terrorism: Are we being too naive? http://www.readwriteweb.com/archives/technology _and_terrorism.php

15. Linden, E.V., 2006. Focus on Terrorism, 6th Edn., Nova Science Publishers, Inc., ISBN: 1-59033617-8, pp: 121.
16. Hildebrand, F.B., 1992. Methods of Applied Mathematics. 2nd Edn., Prentice-Hall, Inc., ISBN: 0486670023.

17. Benjamin, C.K., 1990. Automatic Control Theory. 6th Edn., Prentice-Hall, Inc., ISBN: 9780130510464, pp: 865.

18. Zalman, P.U., Advanced Algebra with Transformations and Applications, Doubleday \& company, Inc., http://library.ksu.edu.sa/digital/32733.html

19. Foley, J., 1995. Computer Graphics: Principles and Practice, 2nd Edn., Addison-Wesley Inc., ISBN: 0201848406, pp: 1284.

20. Foster, I., C. Kesselman and S. Tuecke, 2001. The anatomy of the grid: Enabling scalable virtual organizations. Int. J. High Perform. Comput. Appli., 15: 200-222. DOI: 10.1177/109434200101500302

21. Foster, I. and C. Kesselman, 2003. The Grid 2: Blueprint for a New Computing Infrastructure. Morgan Kaufmann Publishers, ISBN: 1-55860933-4, pp: 748.

22. NASA., 2009. NASA information power grid. http://www.ipg.nasa.org 